\title{
A SURVEY OF HANDICAPPED PERSONS
}

\author{
BY \\ A. LESLIE BANKS, R. G. CARPENTER, AND JAMES A. HISLOP \\ From the Department of Human Ecology, University of Cambridge \\ AND \\ GEORGE NISBET \\ County Medical Officer, Soke of Peterborough
}

Surveys in the medico-social field can be both costly and time-consuming. The purpose of this paper is to show that useful data can be collected by people engaged on their normal work, and without the aid of large ad hoc grants.

Section 29 (1) of the National Assistance Act, 1948, states:

A local authority shall have power to make arrangements for promoting the welfare of persons to whom this section applies, that is to say, persons who are blind, deaf, or dumb, and other persons who are substantially and permanently handicapped by illness, injury, or congenital deformity, or such other disabilities as may be prescribed by the Minister.

A local authority wished to ascertain the number of people for whom provision should be made. It was suggested that a pilot survey of the area be undertaken, and this is now described.

The area to be surveyed consisted of a city which is a railway and industrial centre of growing importance, and the remainder of the administrative county, which is largely agricultural. The estimated mid-1953 population for the city was 53,670 , and for the rural districts 10,350 , giving a total of 64,020 .

\section{METHOD}

In view of what was already known of the number of handicapped persons, it was decided that the survey should cover about 10 per cent. of the houses in the county, and that the houses to be visited should be selected by drawing squares on a large map (scale 1 in 5,000) covering the city and on a smaller map (scale 1 inch to 1 mile) covering the remainder of the county. The squares on the large map measured one inch by one inch, representing an area of approximately 4 acres on the ground. On the county map the national grid squares were used, which represent areas of 247 acres, nearly 62 times larger. In all, the sample consisted of 304 squares on the large map and 21 on the smaller map.

The procedure for selecting the squares to be visited was as follows. Both maps were covered by a complete grid of lines, and this grid was divided into groups of ten squares in an arbitrary manner, but so that neighbouring groups appeared to contain roughly the same number of houses. From each parcel of ten squares one was drawn at random, using random sampling numbers. The 325 squares so chosen to be visited were coloured in, and the maps were brought up to date by marking in new houses on the coloured squares. Some houses overlapped the edges of the coloured squares, but instructions were given when these were to be included and when not. The field workers, who were drawn from the County Medical Officer's staff, called at the houses in the selected squares. If there was no reply at the first call the house was repeatedly revisited, until finally an answer was obtained from every house.

A questionnaire was prepared for use by the field workers. It was felt that in a pilot survey such as this it should be quite simple, as the purpose of the investigation was to determine the approximate number of handicapped persons. It was therefore reduced to the form of asking if there was a handicapped person in the house, and if the answer was in the affirmative, the sex, age, and type of disability.

The Sampling Unit.-The maps showed that many of the coloured squares contained no houses. Those squares were not visited. Thus the sampling unit consisted of squares where, from the map, it appeared that there was one house or more. By the nature of the sampling these units formed an approximately 1 in 10 sample of all squares on which there were houses in the county. 
It is useful to know the distribution of the squares according to the number of houses in the square (Fig. 1). As the number of houses in the squares sampled was not ascertained at the time of visiting, it was decided to count the number of houses per sampling unit from the map, including those houses which had been added when the map was brought up to date. It was found that this could be done on the map covering the city, but was not practicable on the map of smaller scale covering the remainder of the county. The counting was done by two observers working independently. Where there was disagreement in the count a final count was made by a third observer. Of the total of 93 squares on the large scale map on which one or more houses were counted, fourteen had one house on them and only two had between seventy and eighty houses. The distribution of houses per square shows that the number in the survey might be considerably affected by whether or not a particular square was included. Thus, if by chance the two squares with more than seventy houses on them had been omitted the total number of houses would have fallen by at least 8 per cent.

The number of handicapped persons found obviously depends on the number of houses included in the sample. Thus the accuracy of our estimate of the total number of disabled persons depends on whether we did, in fact, sample exactly 10 per cent. of the houses. Fortunately, the number of households in the city was known to one of us (G. N.) and by assuming that there are seldom more than two households sharing one dwelling we can estimate the total number of houses from the census figures (General Register Office, 1952). This would appear to be 16,130 . We estimate that, in fact, 1,786 houses were visited, which suggests that about 170 houses too many were included in the sample covering the city.

Choice of Weight of Function.-To obtain the most efficient estimate of the number of handicapped persons it is necessary to study the way in which the variance of the number of handicapped persons per square changes with the number of houses per square. A simple assumption

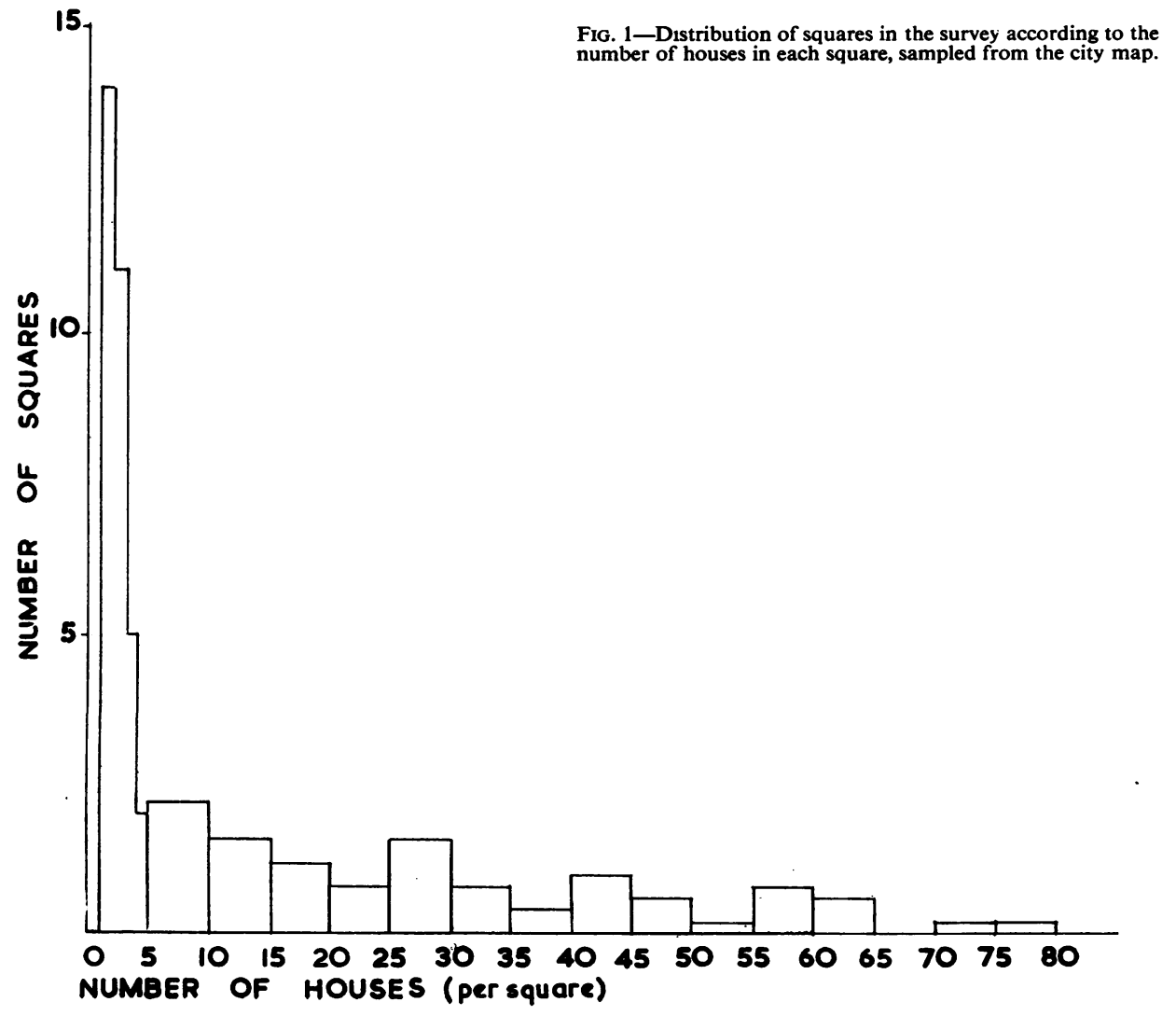


would be that the variance is directly proportional to $n$, the number of houses, although this ignores the effects of such obvious factors as social class, and that some causes of handicap are infectious, $e . g$. those due to tuberculosis.

Grouping the squares by $n$, we may make a rough estimate of the relationship of the variance to $n$. We find that for the range of $n$ in the city the assumption that the variance is directly proportional to $n$ will not be far wrong, although the variance increases more nearly in proportion to $n$ raised to the power of $1 \cdot 3$.

\section{RESULTS}

Estimation of the Number of Handicapped Persons in the City.-Cochran (1953) proves that where:

(i) no house on the square implies no handicapped person;

(ii) the variance may be taken to increase proportionally to the number of houses;

(iii) the relationship between the number of handicapped persons found and the number of houses per square may not be quite linear;

(iv) we know approximately the total number of houses in the city;

then the most efficient estimate of the number of handicapped persons is given by what is known as the "ratio estimate".

As a result of counting the houses, we are able to assess the proportion of handicapped persons to the number of houses. The survey shows that in the city we may estimate that on the average there are eight handicapped persons to every 100 houses. Further we can say that, were this inquiry extended to cover the whole of the city, the average number of handicapped persons in a hundred houses would almost certainly be between six and ten. From this, and from the total number of houses in the city, we estimate the number of people who would have been found had the whole population been surveyed in a similar way. Thus the ratio estimate is that 1,310 handicapped persons would probably have been found in the city, and almost certainly more than 1,000 and less than 1,620.

It will be noticed that, in spite of a fairly intensive survey, we can only predict to within 620 persons, i.e. nearly half the total expected, the numbers that might have been found had we covered the whole city. This is because of the great variability in the number of handicapped people found in squares where there are large numbers of houses. Fig. 2 (opposite), which illustrates this, plots the number of handicapped persons against the number of houses for each square. The estimated ratio of handicapped persons to the number of houses, and confidence limits for this ratio, are also shown. In Fig. 2 we notice that, of squares with over forty houses on them, i.e. the area covered by house and garden of anything less than $60 \mathrm{ft}$. by $60 \mathrm{ft}$., the number of handicapped persons may vary between eleven and one. The four most outstanding points on the diagram have been lettered. " $a$ " and " $b$ " are squares covering what appear to be new council estates in which there is only one handicapped person to between 70 and 80 houses; "c" is a square of over forty houses, of which one contains five cases of tuberculosis; " $d$ " is a square of over forty houses in the older part of the town, in which each of the handicapped persons lives in a different house.

It is interesting to compare the results of the ratio estimate with a less efficient estimate of the number of handicapped persons. Had we not counted the houses on the squares that were visited, our estimate would have been somewhat larger, because we would not suspect that more than 10 per cent. of houses had been visited. The most probable estimate would be 1,450 , and the true value thought to be almost certainly greater than 1,025 and less than 1,875 . Thus, by counting the houses, we have found it necessary to reduce the estimate of the total number of handicapped persons that would have come to light were the whole town covered in like manner, but we are also able to reduce the degree of uncertainty by 27 per cent. of what it would otherwise have been.

Possible Bias of the Ratio Estimate.-There are, however, two possible sources of bias in counting the number of houses on the map. The first is discrepancy in the counting. The first two observers differed in their total count, apart from gross mistakes, by 58 houses (S.E. $\pm 52 \cdot 08$ ). The method adopted for obtaining a final count tended to inflate the total number. There is also some uncertainty about the total number of houses that we estimate as existing in the city. Thus, we may not be entirely correct in scaling down our estimate as we have done.

The other possible source of bias comes from the fact that, in spite of the care with which the instructions were drawn up and carried out, the number of houses actually visited probably differs from the count made from the map. A more satisfactory procedure would be to record the number of houses visited, or, better still, the number of households, which would immediately eliminate both these points of uncertainty.

These sources of bias are additional to those due to the method of questioning. The questions asked were necessarily brief and were not designed to elicit information that people might be unwilling to give. This could cause considerable underenumeration of all causes of handicap. The results of such a survey must always be interpreted within the framework of the questions used. 


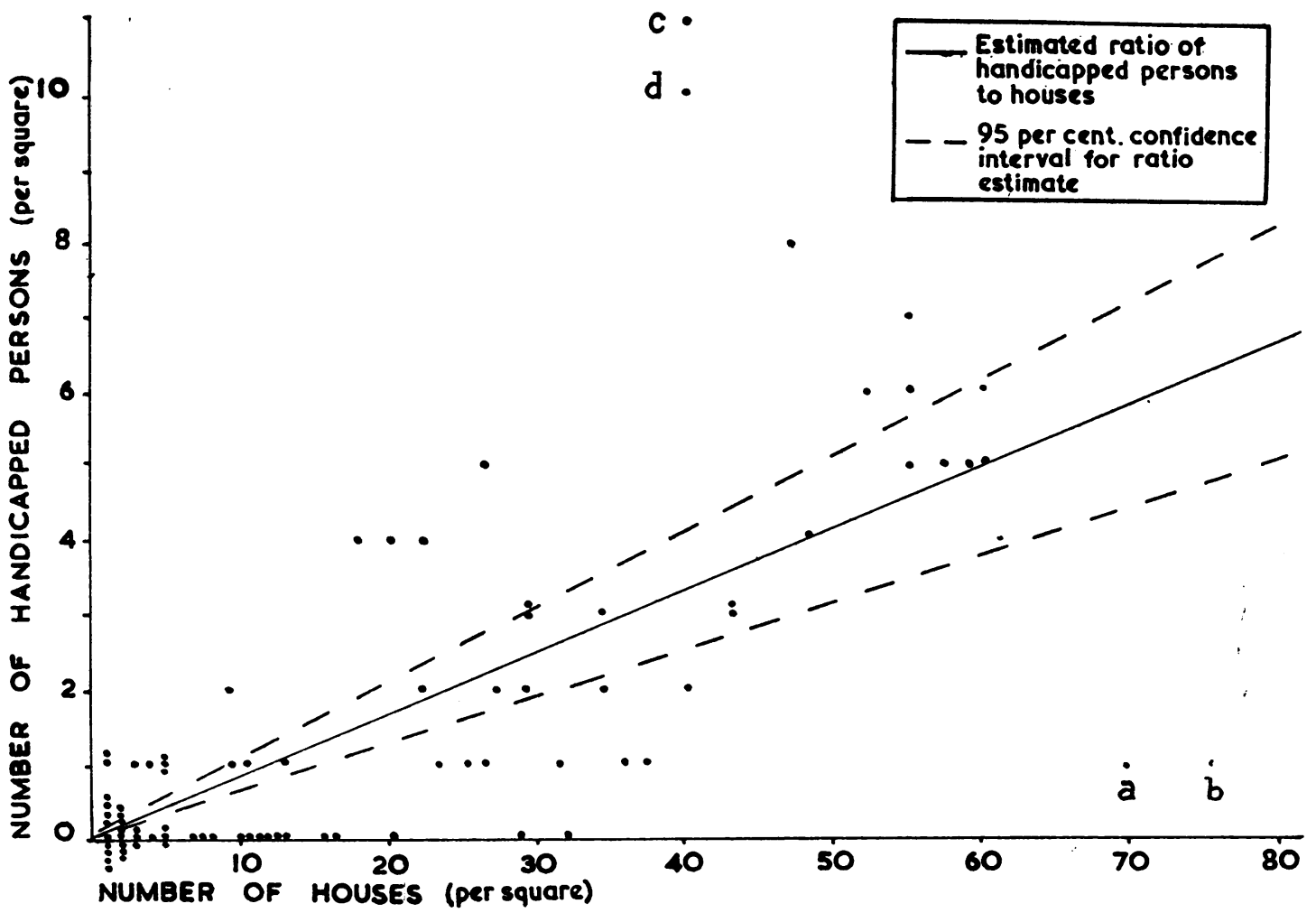

FIG. 2.-Relationship of number of handicapped persons to number of houses in the city of Peterborough. Dots show relationship for each square in the survey. The estimated ratio of handicapped persons to houses, and the 95 per cent. confidence interval for this ratio are also shown.

A further difficulty arises from the fact that different workers may have put different interpretations on the answers. The survey was not designed to give information on this point. A study of such data as were available was made, but the differences found seemed more likely to be related to the social class of the areas visited, similar to those found by Hobson and Pemberton (1956), than to be caused by serious differences between the observers.

Results for the Whole County.-Having examined the findings for the city in some detail, we turn to those relating to the remainder of the county. It was not found possible to enumerate the number of houses that should have been visited, by reason of the smallness of the scale of the map. This information would have been valuable, as the variations in the number of handicapped persons found in different squares leads to some uncertainty as to the total number.

When we put the estimates for the city and the remainder of the county together, using Sukhatme's "d" (Fisher and Yates, 1953) to set our confidence interval, we estimate that the total number of handicapped persons that such an inquiry might bring to light, if it covered the whole county, would most probably be approximately 1,550 , and almost certainly between 1,140 and 1,960 .

Relation of Handicap to Age.-One of the most striking features of the survey is the increase in the number of handicapped persons that is found in the older age groups. Fig. 3 (overleaf) shows the prevalence of handicapped persons by age. This is obtained by multiplying the number of handicapped persons in each age group by 10 (the sample was 1 in 10) and expressing this as a percentage of persons in the corresponding age group of the population as estimated in the 1951 census (General Register Office, 1952).

It is interesting to note that there is a decrease in the prevalence of handicapped males over 65 , but a further increase in that of females over 65 . This is probably due to the greater longevity of females.

Causes of Handicap.-A modified form of a classification used by the Ministry of Health (Ministry of Health, 1953) as a short list of causes of incapacity has been used, as this provided a 


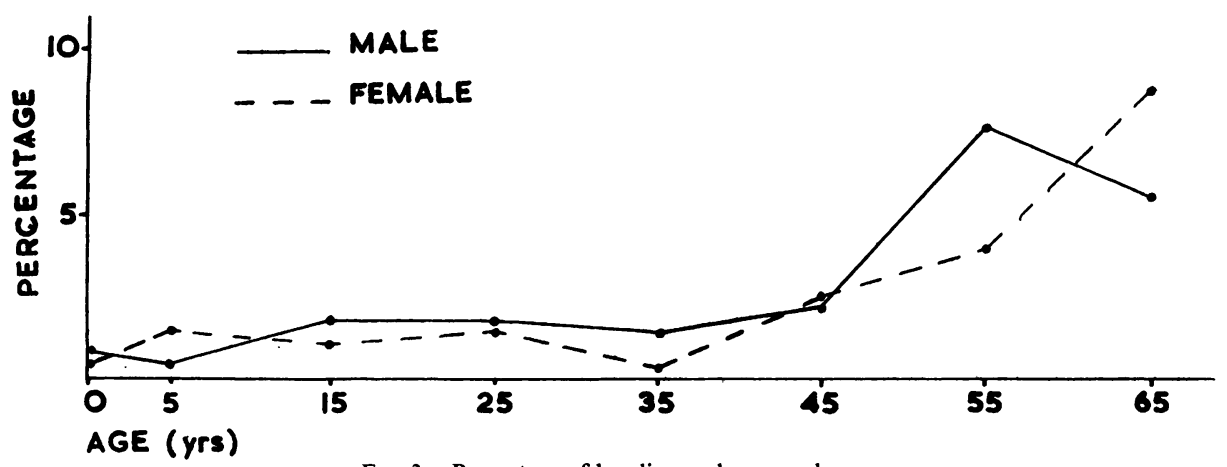

FIG. 3.-Percentage of handicapped persons by age.

natural grouping for the replies. The results are shown in Table $\mathrm{I}$.

TABLE I

CAUSE OF DISABILITY

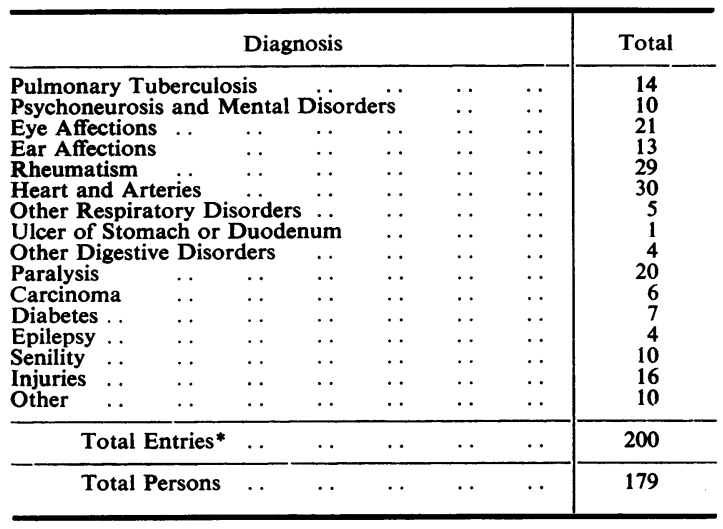

* When one person was recorded as suffering from more than one cause of handicap an entry has been made for each disability.

In the event of more than one cause of handicap being returned, the cause is listed under both headings. The age/sex analysis of these results is shown in Table II (opposite), where we have grouped the subjects into those of under 45 years and those of 45 years and over, 45 being the age at which the prevalence of handicap begins to increase. In brief, Table II shows that in younger females "mental disorder" is the most important cause, followed by tuberculosis, while in older females the chief causes of handicap are rheumatism and heart disease, followed by blindness, deafness, paralysis and senility. In younger males tuberculosis, paralysis, and injuries are the biggest single causes of handicap, while in older males the causes would appear to be heart disease, followed by rheumatism, blindness, and injuries. Further breakdown by age or particular disease is possible, but the numbers become too small to be meaningful.
Comparison of Survey Findings With Existing Lists of HaNdicapped Persons

(a) Deaf and Dumb.--No deaf and dumb persons were found in the survey, which is not surprising in view of the fact that only 19 cases are known in the area.

(b) Blind.-21 cases of total or partial blindess were found. It is not always easy to differentiate total and partial blindness, but it seems that nine of these might be classified as totally blind and twelve as partially blind. It is possible that the definition of totally blind was too strict, for there are somewhat too few in this category. The age distribution is similar to that of the persons on the blind register; we should have expected about fourteen in a 1 in 10 sample, but the deficiency is not statistically significant. The age distribution of those recorded as partially blind is interesting, in that seven of the twelve are under 65 . There are only eight partially blind persons under $\mathbf{7 0}$ registered in the area, and it is most unlikely that seven of them came to be included in the survey. This suggests that the present records of partially blind persons under 65 are deficient.

(c) Mentally Defective.-Five cases of mental deficiency were reported. It is understood that no case was found that was not already under supervision. The number again is somewhat smaller than would be expected in view of the 79 cases already known to be living at home in the area.

(d) Tuberculous.-Fourteen cases of pulmonary tuberculosis were recorded in the survey, which is again less than would be expected, judging by the numbers of notified cases on the register. Some caution must be used before 
TABLE II

CAUSES OF HANDICAP, BY AGE AND SEX

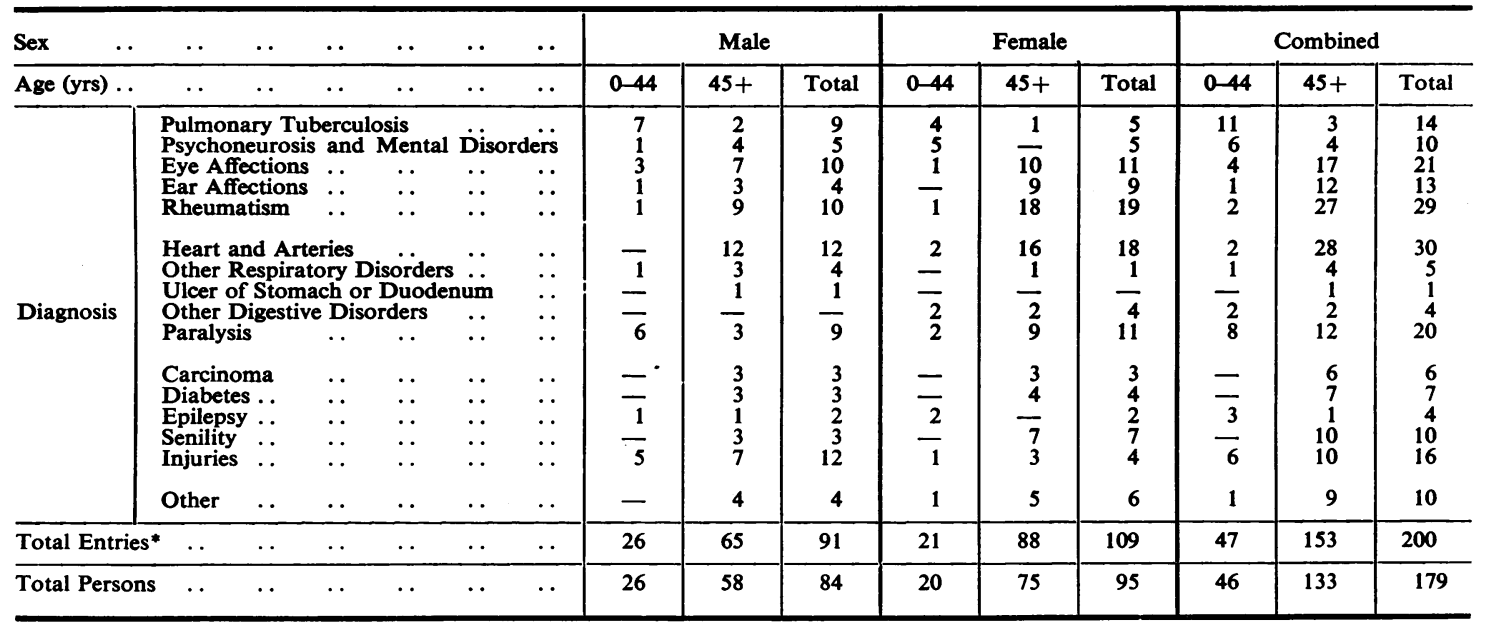

* When one person was recorded as suffering from more than one cause of handicap an entry has been made for each disability.

concluding that the number found is significantly less than would be expected in a 1 in 10 sample survey. As tuberculosis is an infectious disease, it may mean that the cases are not randomly distributed, as was found in the survey. But if one supposed that 50 per cent. of all the 334 notified cases were living in separate houses, we would certainly expect to find more than seven such cases in the sample, though some of the notified cases may be in hospital, or may be quiescent cases whose names remain on the register although they are, in fact, doing a normal day's work.

\section{Discussion}

The sampling technique used has been described in some detail, but in retrospect we do not regard it as the simplest of methods. The maps take some time to prepare, and to interpret them in terms of written instructions for the survey workers is both difficult and time-consuming. If lists of people or property are available it seems better to use these. Such lists have been used and the methods described by a number of other workers (Hobson and Pemberton, 1955; Higgins, 1956; Simonds and Stewart, 1954). If such lists are not available maps can be used, but it would probably simplify the work to modify the boundaries of the grid squares that are included in the sample so that they conform with natural boundaries, as described by Chevry (1946). More elaborate methods of using maps are described by Deming (1950).
The essential feature of this survey is that the results are based on inquiries at houses selected at random in the area surveyed. This enables us to predict the total number of cases that would have come to light, and also to set limits within which the true value would almost certainly lie. It might be complained that these limits are wide, but this is one of the valuable aspects of a random sample survey, that we know how much importance we can attach to our results, and when more work needs to be done.

It is not intended that a pessimistic view be taken of this survey. The information required for preliminary planning of welfare services was, we think, obtained with sufficient accuracy. This information was moreover obtained by workers employed by the local authority with no aid from a research foundation. It is our belief that similar useful and much needed information can often be obtained by small groups of people working together at little or no expense.

\section{SUMmaRY}

A survey designed to ascertain the number of handicapped persons living in the area of a local authority is described.

The field workers were local authority officers untrained in survey work.

The results of the survey showed that approximately 2.4 per cent. of the total population of the county suffered from some form of handicap. A notable feature is the increase in the number of handicapped persons in the older age groups. 
We wish to thank the field workers and other officials of the local authority, Dr. W. L. Smith, formerly Statistician to the Cambridge University Medical School, who helped in the preliminary planning of the survey, and Miss M. E. Baker and Mr.M.S. Hobbs, of the Department of Human Ecology, for their help in this investigation.

\section{REFERENCES}

Chevry, G. (1949). J. Amer. stat. Ass., 44, 373.

Cochran, W. G. (1953). "Sampling Techniques". Wiley, New York.
Deming, W. E. (1950). "Some Theory of Sampling". Wiley, New York.

Fisher, R. A., and Yates, F. (1953). "Statistical Tables for Biological Agricultural and Medical Research", 4th ed. Oliver and Boyd, Edinburgh.

General Register Office (1952). Census, 1951, Great Britain. One Per Cent. Sample Tables. H.M.S.O., London.

Higent. Sample Tables. T.M. D.O., Cochrane, A. L., and Gilson, J. C. (1956). (To be published).

Hobson, W., and Pemberton, J. (1955). "The Health of the Elderly at Home"' Butterworth, London.

(1956). Brit. med. J., 1, 587.

Ministry of Health (1953). "Annual Report for 1951. Part III. On the State of the Public Health". H.M.S.O., London.

Simonds, W. H., and Stewart, A. (1954). British Journal of Preventive and Social Medicine, 8, 139. 